\title{
Representações e práticas de cuidado dos profissionais da saúde indígena em relação ao uso de álcool
}

\author{
Representations and care practices of professionals regarding \\ indigenous use of alcohol
}

\begin{abstract}
Anapaula Martins Mendes (https://orcid.org/0000-0002-3287-797X) ${ }^{1}$ Jose-Oriol Romani Alfonso (https://orcid.org/0000-0001-6939-0711) ${ }^{2}$ Esther Jean Langdon (https://orcid.org/0000-0002-5883-3000) ${ }^{3}$

Marcia Grisotti (https://orcid.org/0000-0003-0389-7100) ${ }^{4}$

Angel Martínez-Hernáez (https://orcid.org/0000-0002-5122-7075) ${ }^{2}$
\end{abstract}

${ }^{1}$ Programa de PósGraduação em Saúde Coletiva, Universidade Federal de Santa Catarina. R. Delfino Conti s/n, Bloco H, Campus Reitor João David Ferreira Lima. 88040-900 Florianópolis SC Brasil. anapsosa@hotmail.com ${ }^{2}$ Medical Anthropology Research Center, Universitat Rovira i Virgili. Tarragona Espanha.

${ }^{3}$ Departamento de Antropologia, Universidade Federal de Santa Catarina. Florianópolis SC Brasil.

${ }^{4}$ Departamento de Sociologia e Ciência Política, Universidade Federal de Santa Catarina. Florianópolis SC Brasil.

\begin{abstract}
Indigenous people's health in Brazil is organized by the indigenous health subsystem, structured according to that of SUS, and described in the National Policy for Health Care of Indigenous Peoples. Alcohol consumption has been regarded as a health issue among indigenous peoples. In this paper, we describe the representations attributed by health professionals concerning alcohol use among indigenous peoples, and how these influence care practices. This is a descriptive ethnographic study based on interviews and participant observation. Analysis and interpretation were made with the support of Software Atlas TI 8.0. Excessive consumption occurs in specific contexts, and professionals view alcohol use as a problem. Drinking patterns vary with ethnicity, religion, and location, thus resulting in the need to develop cultural competencies that support implementation of effective actions and that also allow for collective construction, as stipulated in the policies. A network of supporters is described, among which are indigenous leaders, traditional healers, and the Evangelical Church. The study shows the difficulties of both carrying out policies and implementing actions which correspond to the indigenous peoples' expectations, recognizing the cultural and social rationale related to alcohol use. Key words Health of indigenous people, Alcoholism, Health Policy
\end{abstract}

Resumo A saúde indígena no Brasil está regulamentada pelo subsistema de saúde indígena, estruturado a partir do Sistema Único de Saúde e descrito na Política Nacional de Atenção à Saúde dos Povos Indígenas. $O$ uso do álcool tem sido visto como um problema entre povos indígenas. Nesse artigo descrevemos as representações atribuídas por profissionais de saúde em relação ao uso do álcool entre indígenas e como estas influenciam nas práticas de cuidado. Estudo descritivo baseado em entrevistas e observação participante por inserção etnográfica. Análise e interpretação se deu com apoio do Software Atlas TI 8.0. O uso do álcool é observado como problemático pelos profissionais, e o consumo excessivo é reproduzido em contextos específicos. Os modos de beber variam de acordo com a etnia, religião e local, e isso resulta na descrição da necessidade de desenvolver competências culturais que apoiariam na execução de ações efetivas e contemplassem a construção coletiva prevista nas politicas. Uma rede de apoiadores é descrita, dentre eles, as lideranças, curadores tradicionais e a igreja evangélica. $O$ estudo mostra as dificuldades na efetivação das políticas e na implementação de ações que correspondam às expectativas dos povos indígenas, reconhecendo as lógicas culturais $e$ sociais relacionadas ao uso do álcool.

Palavras-chave Saúde de populações indígenas, Alcoolismo, Política de Saúde 


\section{Introdução}

A saúde indígena no Brasil está regulamentada pelo subsistema de saúde indígena, estruturado a partir do Sistema Único de Saúde (SUS) e descrito na Política Nacional de Atenção à Saúde dos Povos Indígenas (PNASPI). A política propõe atenção diferenciada baseada em diretrizes que tem por objetivo, além de inserir a atenção primária nos territórios, respeitar as especificidades de cada povo, incluindo suas percepções sobre o processo saúde e doença, seus saberes e práticas médicas, assim como sua autonomia através do controle social e, ainda na formação de seus recursos humanos ${ }^{1-3}$.

Enquanto Política de Saúde Mental, o Brasil se alicerça, após o movimento da reforma psiquiátrica, em práticas que centrem o cuidado no usuário e na redução de danos, principalmente, entre os usuários de álcool e outras drogas ${ }^{4}$. No caso da saúde indígena, em 2007, foi apresentada uma proposta de Política de Saúde Mental específica a qual prevê as diretrizes que fundamentam a atenção à saúde mental destes povos. Nesta política estão incluídos o uso de álcool e outras drogas, a formação permanente e a criação de um comitê gestor desta política; considerando como situação emergencial a situação do álcool e do suicídio entre alguns povos indígenas ${ }^{5}$.

$\mathrm{O}$ uso de álcool entre povos indígenas tem sido apresentado, portanto, como um importante problema de saúde. Contudo, Ghiggi Jr e Langdon ${ }^{6}$ e Langdon ${ }^{7}$ descrevem uma certa dificuldade em se traçar um consenso sobre o que, realmente, pode ser caracterizado como alcoolismo, dados os diferentes modos de consumo padronizados em acordo com especificidades apresentadas pelos povos indígenas e que não nos permite generalizar ou aproximar estes modos de beber daquilo que é padrão para a sociedade não indígena. Esta percepção nos parece ser o foco das diretrizes propostas pela política específica criada pelo Ministério da Saúde que protagoniza os povos indígenas desde o processo de planejamento, avaliação e desenvolvimento de ações relacionadas ao tema.

Muitos dos estudos realizados entre povos indígenas têm se baseado no conceito de alcoolização, proposto por Menéndez ${ }^{8}$ que aborda este "agravo" de uma maneira mais contextual, o que nos permite observar os diferentes modos de beber de cada grupo social e cultural, assim como compreender as repercussões e consequências positivas e negativas em relação ao uso de bebidas alcoólicas. Considerando então o uso em sua amplitude, e não somente como problema de saúde, sem focar somente nos sujeitos considerados "alcoólicos dependentes", sejam eles excessivos, moderados ou abstêmios. Desta forma o uso de álcool também pode ser analisado em seu contexto não somente como problema, mas também enquanto prática social e cultural ${ }^{8-10}$.

Souza e Garnelo ${ }^{11}$, pensando este conceito de alcoolização, indicam que existe uma necessidade em se analisar o consumo do álcool levando em consideração os contextos de inserção dos sujeitos, sua cultura e sua história, não apenas o "uso problemático", mas buscando significados para o beber. Langdon ${ }^{7}$ reforça dizendo que necessitamos de uma abordagem mais "cultural/coletivo/ multifatorial" buscando uma ampliação no enfoque sobre a situação que nos permita criar estratégias que tenham maior impacto na situação.

Sabe-se que o uso de substâncias psicoativas, incluindo as bebidas alcoólicas, possuem inúmeras representações para diferentes grupos, e precisamos compreender os diferentes modos de beber das sociedades indígenas e que significados eles trazem, o que é de fundamental importância para que possamos entender "como e porquê beber" nestes contextos diversos, assim como compreender como os rituais e as regras estabelecidas pelos povos indígenas exercem "implicações simbólicas e sociopolíticas reguladoras" que necessitam ser consideradas no momento do planejamento de ações pelas equipes de saúde ${ }^{7,11,12}$.

O objetivo deste artigo é descrever as representações e significados atribuídos por profissionais da saúde indígena ao uso de álcool em comunidades indígenas, assim como descrever como isso influencia no desenvolvimento das práticas de cuidado entre povos indígenas no extremo norte do estado do Amapá e as relações com as diretrizes das políticas específicas estabelecidas, com foco no conceito ampliado de alcoolização.

\section{Aspectos metodológicos}

Trata-se de uma etnografia realizada com profissionais lotados nos serviços de saúde indígena no município de Oiapoque, Amapá. Este município conta com uma população aproximada de 7.000 indígenas, cerca de $30 \%$ do total de sua população, dos grupos étnicos: Galibi Marworno, Karipuna, Galibi Kali’na e Palikur, distribuídos em três terras indígenas.

A etnografia foi baseada em observações participantes, desenvolvidas durante a efetivação de atividades assistenciais conjuntas, de pesquisa 
e de educação em saúde, registradas através de diário de campo e vídeos. As atividades de campo se iniciaram no ano de 2016 a partir de uma reunião do Conselho Distrital Indígena, que convidou um dos pesquisadores a desenvolver ações relacionadas ao consumo do álcool entre os povos indígenas.

A partir disto foi desenvolvido projeto de pesquisa que foi efetivado entre os anos de $2017 \mathrm{e}$ 2018 com a inserção do pesquisador em reuniões, atividades de educação em saúde e de extensão que tratavam do tema. Estas atividades incluíram, além da discussão sobre o tema, atividades de educação em saúde, sessões de teatro do oprimido, palestras, rodas de conversa e trabalho conjunto à equipe de saúde indígena.

Também foi realizada entrevista semiestruturada com 11 profissionais (Tabela 1), de um total aproximado de 20 trabalhadores; não contabilizados neste número os Agentes Indígenas de Saúde, que não fizeram parte desta etapa, devido à problemas logísticos e administrativos, para o ingresso nas aldeias no período de realização. Os demais foram entrevistados em locais fora da aldeia em seus períodos de folga.

A seleção foi realizada através de convite formal realizado pessoalmente, ou por telefone e

Tabela 1. Perfil dos profissionais entrevistados de acordo com a faixa etária, sexo, etnia, profissão e tempo de trabalho na Saúde Indígena (SI).

\begin{tabular}{lc}
\hline \multicolumn{1}{c}{ Perfil } & Número \\
\hline Profissão & 02 \\
Enfermeiros & 01 \\
Assistente Social & 01 \\
Farmacêutico & 07 \\
$\quad$ Técnico em Enfermagem & \\
Sexo & 05 \\
F & 06 \\
M & \\
Faixa etária & 04 \\
20-29 anos & 03 \\
$30-39$ & 01 \\
$40-49$ & 03 \\
$\quad \geq 50$ & \\
Etnia & 05 \\
Pardos & 06 \\
Indígenas & \\
Tempo de trabalho na SI & 03 \\
Até 5 anos & 05 \\
Entre 6 e 9 anos & 03 \\
$\geq 10$ anos & \\
\hline Fo Regis dsentrisas &
\end{tabular}

e-mail. A partir do aceite do profissional mediante assinatura do Termo de Consentimento Livre e Esclarecido, foi agendado local e horário oportuno para a realização das entrevistas as quais foram gravadas.

A análise e interpretação se deu a partir da lógica da hermenêutica dialética que propõe compreender como a práxis se dá em relação aos discursos dos sujeitos, buscando interpretar os sentidos com base na linguagem, assim como dialogando de forma crítica com o que foi observado enquanto trabalho de campo somado ao referencial teórico, tomando como base o contexto de inserção do grupo, sujeito e objeto do estudo $^{13-15}$.

A organização dos dados foi realizada com o apoio do software ATLAS TI 8.0, o qual foi descrito anteriormente por Forte et al. ${ }^{16}$ e Martorell -Poveda et al. ${ }^{17}$ como potencial apoio na organização e leitura dos dados coletados em conjunto com a análise baseada na prática da hermenêutica dialética. Os documentos foram transcritos literalmente, lidos e organizados em conjunto com os vídeos no software, onde foram realizadas releituras e ordenação das citações através da atribuição de códigos ou categorias primárias, criadas de forma indutiva a partir das leituras iniciais e triangulados de acordo com as observações realizadas durante o trabalho de campo com o objeto e os objetivos propostos.

Após a organização dos dados se buscou compreender os diversos sentidos e símbolos presentes nas diferentes formas de linguagem apresentadas pelos profissionais a partir da elaboração de uma rede de relações. Quatro categorias emergiram a partir desta organização dos dados: as representações e significados, competência cultural, rede de apoiadores, e atitudes e práticas profissionais. Estas três últimas foram agrupadas na descrição por estarem presentes e compreendidas de forma complementar, quando analisados os discursos e observações.

\section{Representações e significados atribuídos ao uso de álcool entre povos indígenas}

De maneira geral os profissionais observam, nos territórios onde desenvolvem seu trabalho, um consumo baseado no exagero. Palavras como "muito" e "bastante" surgem e são expressas de forma a descrever como são representados os modos de consumo pelos povos indígenas com quem trabalham. A situação é caracterizada como problemática, de forma geral, fundamentada na caracterização de excesso, a qual não surge 
diretamente relacionada a um padrão ou quantidade, mas sim às consequências trazidas pelo consumo abusivo:

[...] quase sempre é problemático porque assim eles começam na diversão, só que nessa diversão da bebida né eles perdem o controle, começam a beber, beber e perdem o controle.

Alguns contextos de consumo são destacados como determinantes deste padrão de abuso. Dentre eles estão as festas dos santos, vinculadas à igreja católica, historicamente inserida nos territórios indígenas, desde o processo de colonização. As festas dos santos, de acordo com os profissionais, estimulam o consumo de bebidas alcoólicas de forma desenfreada, ou seja, sem controle e durante muitos dias ou semanas:

E quando tem festa na aldeia a gente sabe né que eles fazem o uso, [...] em festas de santos. São João, sempre eles fazem festa, fazem uso bastante de álcool desde destilados até fermentados.

O uso de álcool também se difere em acordo com o local ou o grupo étnico com quem se trabalha. Os indígenas que residem em aldeias onde são em sua maioria evangélicos, são caracterizados como menos problemáticos em relação ao consumo de bebidas alcoólicas, considerando que existe um veto ao uso quando o indígena se "converte" a esta religião; porém isso tem sido observado entre outros grupos étnicos, em outros territórios onde a igreja evangélica também tem se instalado:

[...] era uma aldeia, que não tinha, não fazia muito uso da bebida alcoólica. As pessoas diziam que, quase em sua totalidade devido à entrada do trabalho de evangelização.

É observada uma troca importante nos padrões de consumo, que antes estavam concentradas no uso do caxiri - bebida tradicional produzida pelos povos da região - e que, atualmente, estimula a ingestão de bebidas industrializadas como a cerveja e a cachaça, esta última mais presente nos locais onde ainda não há energia elétrica. Neste contexto também se altera quem bebe; antes bebiam jovens adultos, hoje se observa o consumo de álcool industrializado muito mais cedo, o que é trazido como preocupação pelos profissionais:

A bebida deles trazia menos problema, porque a bebida deles ela não é tão forte quanto a outra que vem de fora.

Antes eles bebiam era mais o caxiri que era só isso que eles bebiam antigamente que os mais velhos acostumavam de fazer... não bebia criança, hoje em dia a gente vê assim de quase 10, 11 anos já está bebendo, mas antigamente não tinha essas coisas assim, era um respeito muito grande assim com as famílias.

[...] bebidas tradicionais deles, eles tão usando mais com uma baixa frequência num momento de festa, festejos, alguma comemoração, dança do turé entre outras. Mas a maioria das bebidas em si são bebidas industrializadas.

O uso problemático também está vinculado à falta de cumprimento das regras e normas sociais instituídas pelos povos indígenas o que gera conflitos que nem sempre podem ser sanados pelos profissionais, os quais direcionam a situação a uma rede de apoiadores estabelecida em acordo com sua inserção no território. Dentre as formas de "punição" construídas pela própria sociedade indígena, independente da conduta profissional, a faxina aparece como principal forma de castigo. Trata-se de um momento de exposição do sujeito à comunidade indígena, esta ação além de promover a "vergonha” também sujeita o indígena a situações de extrema carga de trabalho, o qual normalmente seria desenvolvido por um grande grupo de pessoas e que acaba a cargo de uma única:

[...] punir né, tem as faxinas que eles dão. É as leis deles né, que quando alguém faz a coisa errada então eles têm as leis deles que é feita por eles mesmos, como colocar pra fazer uma faxina...uma punição.

Dentre as situações ditas como problemáticas são citadas as que geram violências, doméstica ou não, outros conflitos familiares, falta ao trabalho, à escola ou a outros compromissos; existe um foco muito centrado no contexto familiar, assim como na desarticulação com as normas de organização social que configura este território:

Essa problemática de drogas né, quer dizer do álcool, mas o álcool também é uma droga, droga lícita, mas é uma droga, de uma certa forma a gente tem percebido muito conflito familiar, tem tido vários problemas aqui, teve uma época que a gente tinha várias situações, de espancamento da mulher...

É meio complicado o uso do álcool né, porque traz muita consequência ruim, assim....entre eles, briga, desentendimento na família e tem vezes que eles ficam agressivos, com eles mesmos; além da violência, os constrangimentos que a família passa né, assim né, envolvendo outras famílias...problemas sociais e às vezes assim, jovem em vez de estarem em sala de aula tão usando bebida, fazendo coisas que não devem. 


\section{Estabelecendo redes, competências profissionais e instituindo suas práticas}

O desenvolvimento de habilidades específicas necessárias para abordar temas como o de uso de bebidas alcoólicas, nomeamos como competência profissional, a qual foi representada em alguns momentos pelos profissionais. Eles compreendem a necessidade de entender melhor os saberes e práticas envolvidas no uso do álcool e de estabelecer ações que atendam àquilo que realmente é observado como necessidade pelos povos com quem se trabalha, dada a diversidade presente na região onde estão inseridos:

[...] todo profissional tem que estar capacitado, treinado pra lidar com cada situação, porque é uma coisa trabalhar com o dito indígenas ou não indígenas.

Tem que ser um trabalho diferenciado com eles né.

A gente trabalha com 3 povos, os Galibi Marworno, Palikur e os Karipuna.

O desenvolvimento destas competências possibilita a efetivação de um cuidado culturalmente adequado e realizado de forma mais organizada, considerando que muitos se veem sobrecarregados em relação às diferentes práticas a serem executadas em diferentes programas de saúde. Isso influencia nas suas representações e também no desenvolvimento destas ações desde seu planejamento. Para tanto, alguns profissionais referem que seria interessante ter uma equipe que desenvolvesse um trabalho específico sobre este tema e reconhecem a necessidade de estabelecer uma prática de atenção diferenciada.

[...] é complicado às vezes você trazer uma abordagem pra eles e colocar o dano que traz o álcool.

Com base no desenvolvimento destas competências se estabelece, então, uma rede hierarquizada de apoiadores que influenciam de forma direta as atitudes e práticas destes profissionais. Algumas figuras são extremamente representativas nestes territórios, se iniciando pelas "lideranças", aqui descritos como caciques, conselheiros, curadores, entre outras pessoas que surgem como referência para a estruturação dos modelos organizacionais estabelecidos no contexto indígena, como ex-caciques e professores.

Para os profissionais estas pessoas são aquelas que detém o poder e, consequentemente, a responsabilidade sobre a situação gerada pelo uso do álcool, em específico a caracterizada como problemática; considerando que, geralmente está vinculada à um conflito social com intrínseca relação com o rompimento destas regras estabelecidas pelos povos indígenas. Para além das lideranças, a FUNAI e a Polícia também surgem com características similares: mediadores de conflitos e reguladores, balizados em uma legislação:

[...] quando entra muita bebida, aí o cacique tem que ser duro com eles aí no caso quem não obedece, quem briga, quem faz coisa errada, durante a bebida...o cacique tem direito a punir aquela pessoa, de colocar, por exemplo numa faxina, ou então tem que fazer alguma coisa, acionar a polícia se tiver alguma coisa grave no meio entendeu.

É compreendido pelos profissionais que são as lideranças quem podem interferir nos modos de vida e nos padrões de organização social; geralmente suas ações são fomentadas por leis, regras e normas, previamente estabelecidas e que regulam desde o ingresso e o comércio das bebidas dentro dos territórios até os dias e horários que são permitidos o uso pelos povos indígenas. Para além disso, também estabelecem as normas relacionadas às possíveis formas de punição, como descrito anteriormente, que podem ser empregadas de acordo com o nível de desobediência e com o impacto gerado por tal ação.

Neste contexto alguns trabalhadores são vistos como melhor qualificados para lidar com estas situações, como no caso dos Agentes Indígenas de Saúde (AIS) e técnicos de enfermagem indígenas, elencados como integrantes desta rede de apoio. O que foi observado é que estas figuras, por estarem inseridos enquanto população nestes contextos, possuem muito mais propriedade para intervir em uma situação que necessite abordar o tema do uso do álcool. Os espaços da escola e os professores também foram apresentados como potenciais apoiadores, considerando, principalmente as ações que visam as práticas de educação em saúde.

Para a maioria dos profissionais, um importante apoiador na "resolução do problema do álcool" é a igreja; especialmente a evangélica, religião seguida predominantemente pelos povos Palikur, porém, nos últimos anos tem se fortalecido e se inserido também entre os demais grupos étnicos aqui estudados:

[...] eu gosto de falar do evangelho, às vezes o indígena ta lá vira evangélico e para de beber, pela religião.

[...] eu acho que pode ser a melhor experiência que eu já tive.

Nesta segunda citação o profissional faz referência à igreja evangélica e à conversão dos indígenas que resultava em abstinência, o que era exposto como resolutivo, quando questionado 
sobre experiências exitosas em relação a abordagem do tema; contrapondo-se à forma como é observada a ação da igreja católica, que, de acordo com eles, tende a estimular um uso descontrolado de bebidas alcoólicas pelos povos indígenas, assim como possibilitar os espaços de uso abusivo caracterizados, principalmente pelas festas de santos:

[...] a gente não vê eles usando a bebida indígena né mas sim caixas e caixas de...vou colocar nome né...51, caixas e caixas de cerveja...né, e tem as festas deles que tem o festeiro que cada festeiro tem que dar uma quantidade de bebida e de álcool.

Também foram traduzidos como integrantes desta rede, por alguns profissionais, instituições como os alcoólicos anônimos e uma comunidade terapêutica conhecida como "fazenda da esperança", enquanto desenvolvedores de técnicas capazes de sanar um problema e, algumas práticas pensadas, se fundamentam nestes modelos que se centram na resolução da problemática através da abstinência o que contraria claramente o que se propõe enquanto política de cuidado aos usuários de álcool e outras drogas e que reproduz, muito provavelmente, pessoalidade nas posturas profissionais, que deixam de seguir as orientações protocolares e veem uma comunidade terapêutica como apoio no que tange a situação de consumo do álcool.

A figura do gestor do DSEI foi trazida na descrição da rede como contraditória enquanto apoiador, sendo que os profissionais sentem falta do apoio destes no desenvolvimento das atividades, principalmente em relação à instrumentalização para a execução das ações e na formação destes profissionais que, em acordo com a PNASPI, deveria ser realizada pelo DSEI. Neste sentido se compreende que para além do fornecimento de insumos e materiais, descrito por alguns profissionais, fica prejudicada a diretriz de formação dos recursos humanos e, consequentemente o desenvolvimento das competências culturais necessárias para a implementação do cuidado.

A partir da disponibilização destas ferramentas caracterizadas como necessárias ao desenvolvimento das ações, os profissionais estabelecem quais atitudes e práticas podem ser desenvolvidas; destacando-se as atividades com foco na educação. Palestras, oficinas, aconselhamento individual foram expressas, por praticamente todos, como sendo estratégias importantes e que deveriam ser contínuas, mesmo que por alguns não se efetive. Esta não efetivação em acordo com eles está vinculada a diferentes aspectos, desde a limitação de insumos e recursos humanos, até questões relacionadas às dificuldades em relação ao tema e métodos de abordagem, ao apoio da gestão e ao lugar estabelecido por cada profissional em relação ao trabalho.

Esta última ocorre por conta de uma espécie de distanciamento do tema e de uma limitação nas ações de saúde que não se articulam. O lugar do trabalho estabelecido por cada profissional se configura a partir de códigos previamente criados por eles mesmos, seja no processo de formação ou na própria estrutura dos serviços. A exemplo, os assistentes sociais ou farmacêuticos não desenvolvem atividades relacionadas ao tema, pelo contrário, se posicionam referindo ter outras atribuições e que existem profissões específicas para tal ação como enfermeiros e psicólogos.

As escolas são postas como espaços potenciais para o desenvolvimento destas atividades. Apesar deste local ser considerado importante foram poucos os profissionais que referiram desenvolver atividades, de forma organizada e contínua, com o apoio dos professores, dentro destes espaços. De acordo com os profissionais é necessário focar nas crianças e na população mais jovem a partir da representação dos malefícios trazidos pelo uso de bebidas alcoólicas, incluindo as possíveis doenças e agravos atribuídos ao uso exagerado.

\section{Discussão}

Em relação ao consumo exagerado descrito, estudos anteriores atribuem estes episódios baseados em excessos aos diversos estilos de beber entre diferentes povos indígenas. As longas "bebedeiras" nem sempre são vistas como situações problemáticas pelos indígenas, diferente do que está representado pelos profissionais aqui abordados ${ }^{7,9,18,19}$. Dias $^{20}$ quando descreve suas impressões acerca do uso de álcool entre os povos indígenas na Terra Indígena Uaçá nos apresenta um estilo de beber que a seu ver "se caracteriza por uma ética de imoderação, do exagero e da renúncia parcimônia".

Os fatores que influenciam como, quando e onde se bebe são múltiplos e, entre povos indígenas, geralmente não se dão de forma isolada, mas inclui a todos enquanto sociedade, mesmo estando cercados de contextos e conceitos instituídos pelo contato interétnico ${ }^{21}$. O uso característico de bebidas nas festas, funerais, na construção das roças, casas, espaços coletivos, rituais de cura, são apresentados em diferentes estudos, 
mas nem sempre com a mesma conotação. Podem ser atribuídos a um momento de diversão, ao estabelecimento de relações sociais e políticas, para manter-se forte e alerta no desenvolvimento de determinada atividade, festejar ou chorar pela ida de um ente querido, aproximar-se dos espíritos, homenagear a determinada entidade, estabelecer processos terapêuticos, entre outros significados simbólicos ${ }^{7,11,18,20,22}$.

A intervenção da igreja evangélica nas práticas culturais e nos espaços de consumo de bebidas e outras drogas tem sido resinificada nestes contextos sendo reconhecida, inclusive, como suporte à biomedicina, numa espécie de "eficácia simbólica" atribuída pelos indígenas e por profissionais, que os mantém em lugares distintos, mas que têm diferentes iniciativas em relação às intervenções necessárias para minimizar os problemas gerados pelo uso de álcool. É importante salientar que não somente o uso abusivo é centro da intervenção, mas qualquer espécie de consumo, com foco na abstinência como requisito para a inserção nos espaços pentecostais, contradizendo as diretrizes políticas estabelecidas para o cuidado destes usuários ${ }^{23}$.

Rivera $^{23}$ em sua tese trata estas situações de transformação cultural como uma "nova racionalidade" que se estrutura de forma a superar as expectativas em relação às práticas biomédicas e tradicionais tornando-se um "saber médico pentecostal". Nesta perspectiva transformam-se os sentidos e os significados atribuídos ao processo saúde e doença e, desta forma, também se alteram os processos terapêuticos. Esta reelaboração simbólica, como cita Vallverdú ${ }^{24}$, apesar de fortalecer e reconfigurar, de forma direta, os modelos organizacionais, políticos e sociais destes povos, também tem sido território de conflito "por desafiar as estruturas de controle político e econômicos tradicionais" e ao mesmo tempo poderia ser considerada como uma base ideológica da reformulação dos poderes políticos e econômicos contemporâneos.

Em relação ao uso das bebidas tradicionais já não serem mais foco nos momentos de consumo do álcool, isso nos parece representado por diferentes adaptações culturais realizadas ao longo do tempo. A esta transição ou incorporação de outras bebidas alguns autores referem que a ação, muitas vezes, parece ser intensificada, no sentido de que a cachaça ou outra bebida fermentada industrializada possui um efeito maior em relação à bebida tradicional, quando pensamos em teor alcoólico. Contudo os motivos que levam a esses momentos de exagero coletivo ainda pos- suem significados construídos e constituídos socialmente mesmo que em novos contextos de consumo como os descritos pelos profissionais de saúde $7,18,22,25$.

Sobre as situações problemáticas apresentadas como resultado do consumo exagerado de outras bebidas ou pela "troca" da bebida tradicional pelas industrializadas Oliveira et al..$^{25}$ descrevem situação similar entre os Maxakali onde as lideranças indígenas também reconhecem em seus discursos as consequências negativas que vêm trazendo esta alteração nos padrões de consumo destes povos, o que corrobora com os discursos dos profissionais de saúde apresentado por Maciel et al. ${ }^{26}$ entre os Potiguara.

Da mesma forma, sustenta Quiles ${ }^{18}$ ao falar sobre os comportamentos estabelecidos nos momentos de consumo exagerado de álcool entre os Bororo, caracterizado pelo uso prolongado de bebidas, por todas as faixas etárias, no qual "geralmente a aldeia inteira acompanha todas as fases da bebedeira", passando por situações de agressividade e violência e geralmente se encerram com o "cair anestesiado".

Dias $^{20}$ chamava a atenção ao fato deste ato de "beber até rezar", tanto da bebida tradicional como da cachaça ou outra bebida, se estabelecer visando o fim da bebida; por este motivo o consumo as vezes se dava durante dias e ainda se dá como descreveram os profissionais, porém seguia com dias, semanas e até meses de abstinência. $\mathrm{O}$ mesmo estudo trouxe, no discurso de alguns indígenas, a representação de um certo distanciamento do caxiri quando se bebia muita cachaça e que essa prática trazia consequências nem sempre bem vistas por eles.

De acordo com a PNASPI um dos focos no desenvolvimento da atenção primária é a proposta de atenção diferenciada, que se dá, também, a partir da formação dos recursos humanos que deveriam, portanto, desenvolver esse "cuidado culturalmente apropriado". Essas habilidades seriam base para que se configurassem as diretrizes propostas pela política, o que nem sempre se efetiva e se reflete de maneira direta na insegurança representada pelos profissionais de saúde e também nos resultados relacionados a situação de saúde destes povos ${ }^{3,27}$.

As políticas específicas de saúde indígena e a de saúde mental fomentam essa proposta de construção coletiva e de representação dos povos indígenas, a partir destes atores sociais considerados importantes, desde o planejamento, monitoramento e avaliação das situações e atividades propostas no que tange à saúde desta população, 
incluindo as relacionadas com o uso de álcool, como citamos anteriormente. Tudo isso valorizando e respeitando as especificidades de cada povo e estimulando a formação permanente dos profissionais de saúde lotados nestes contextos diversos visando a implementação das ações de forma efetiva ${ }^{1,5}$.

As condições impostas pela igreja evangélica nestes territórios se baseiam em regras controversas àquelas presentes entre os povos indígenas, propiciando uma inversão de sentidos baseadas em novas interpretações relacionadas aos simbolismos anteriormente atribuídos, inclusive em relação ao processo saúde, doença e atenção. Onde os significados do que é bom e as representações divinas se apresentam em prol de uma conversão obrigatória e salvadora e que ao mesmo tempo dialoga com conflitos importantes em relação aos modelos organizacionais que orientam os contextos indígenas ${ }^{23,24}$.

De acordo com Rivera ${ }^{23}$, a "estrutura simbólica das práticas terapêuticas pentecostais geralmente incitam a conversão" e esta reflete na aceitação de que a produção social do saber pentecostal é verdadeira e única e isto deve ser reproduzido por todos os que se inserirem nos espaços da igreja. Dentre as bênçãos mais comumente reproduzidas está a de que "seguir o caminho de Deus" faz com que você seja apresentado como uma boa pessoa e, como beber não está conceituado como algo bom, você não beberá mais e desta maneira encontrará a salvação.

Devemos esclarecer que não foi especulada a atribuição religiosa dos profissionais inseridos no estudo, mas se percebe que alguns deles fazem parte de um grupo que reproduz seus saberes eclesiásticos em seus espaços de trabalho, o que não pode ser generalizado. Neste sentido é necessário estabelecer um certo "relativismo" entre estes profissionais, o que também está presente quando falamos do desenvolvimento de habilidades e competências para o desenvolvimento do seu trabalho $0^{9,27,28}$.

O que deveria estar instituído enquanto prática, pensando as diretrizes políticas, seria, principalmente, dotar de conhecimento, informação e orientação a população com quem se trabalha, permitindo que o indivíduo, família ou sociedade possa escolher e gerir suas relações com o álcool, assim como seu plano de cuidado. O que também está bastante claro na Política de Saúde Mental no Brasil a qual se fomenta na proposta da redução de danos que, a partir de um modelo de negociação, atribui autonomia aos sujeitos, inclusive na construção do seu plano terapêutico ${ }^{4,5,28}$.
De acordo com Souza ${ }^{9}$ parece que existe dificuldade entre os profissionais de saúde em desenvolver ações de prevenção e promoção de saúde no âmbito das doenças crônicas não transmissíveis, em especial por elas exigirem mudanças comportamentais, às quais os mesmos não podem gerir de forma direta e que são autônomas. Esta situação também se reflete na dificuldade em se inserir em contextos étnicos culturais diversos quando os processos de formação em nível acadêmico estão hegemonicamente médico-centrados.

Souza e Garnelo ${ }^{29}$ descreveram, partindo de discussões anteriores realizadas por outros autores, a dificuldade na inserção de profissionais de saúde em contextos diversos, em especial entre grupos que reproduzem padrões culturais específicos, como no caso dos povos indígenas, sendo ainda mais desafiador o desenvolvimento de trabalhos relacionados à saúde mental, no âmbito da atenção primária, quando o foco no cuidado ao usuário de álcool "configura um importante obstáculo a ser enfrentado pelos profissionais".

\section{Conclusão}

As representações profissionais aqui descritas nos parecem estar centradas em uma única dimensão e direção, onde trabalhadores assumem uma posição onde são considerados majoritariamente os conceitos biológicos e biomédicos, apreendidos durante processo de formação. Neste caso existe maior dificuldade em realizar ações realmente efetivas e que dialoguem com as expectativas dos povos indígenas enquanto coletivo, principalmente quando a atuação destes profissionais está envolvida por questões morais e não-laicas. Esta perspectiva individualizante não é foco das diretrizes políticas pensadas para estes contextos, tampouco a proposta de atenção diferenciada.

Os profissionais de saúde são inseridos no processo de trabalho sem desenvolver as competências necessárias para planejar, executar e avaliar ações no âmbito dos contextos étnicos e culturais diversos que permeiam o trabalho com povos indígenas no Brasil.

Desta forma o consumo do álcool é observado pelos profissionais sem levar em conta as lógicas sociais e culturais de consumo estabelecidas pelos povos indígenas com quem trabalham. Sem considerar que estes modos de consumo estão permeados por ações de reciprocidade, controle e regulação que representam muito mais que uma limitação em relação à quantidade, mas possuem uma conotação ritualística e simbólica. Estas li- 
mitações na compreensão destes comportamentos e práticas fazem com que estes profissionais foquem em um modelo individualizante o que é contraditório às lógicas das sociedades indígenas de maneira geral e às políticas de saúde mental indígena no Brasil.

O reconhecimento destas dimensões socioculturais das formas de beber indígenas seria a base que permitiria realizar políticas de redução de danos em relação ao álcool, já que as metodologias dialógicas, de escuta e reconhecimento do outro, são capazes de garantir maior capacidade em relação a implementação destas políticas. $\mathrm{Ou}$ seja, devem ser considerados os reais interesses dos indígenas e o capital social gerado por estes povos, assim como as dimensões comunitárias do beber expresso pelos rituais de consumo.

Porém, o que observamos é que os profissionais de saúde não se baseiam no simbolismo local e nas mudanças que esta população realmente tem interesse em promover no processo de planejamento, avaliação e implementação das práticas voltadas a este tema, contradizendo, portanto, os marcos regulatórios previstos nas políticas específicas aqui tratadas e reduzindo as possibilidades de êxito no desenvolvimento das suas ações.

\section{Colaboradores}

AM Mendes: elaboração e desenvolvimento do projeto, coleta dos dados e análise dos resultados, escritura e estruturação do artigo. M Grisotti e EJ Langdon: apoio no desenvolvimento e estruturação do projeto, análise dos dados; escritura e estruturação do artigo. JOR Alfonso e A Martínez -Hernáez: apoio na análise dos dados, escritura e estruturação do artigo.

\section{Agradecimentos}

O desenvolvimento do projeto foi financiado pela Bolsa Fundação CAPES/PDSE. 


\section{Referências}

1. Ministério da Saúde (MS). Fundação Nacional de Saúde (FUNASA). Política Nacional de Atenção à Saúde dos Povos Indígenas. $2^{\mathrm{a}}$ ed. Brasília: MS, FUNASA; 2002.

2. Garnelo L, Pontes AL. Saúde Indígena: uma introdução ao tema. Brasília: MEC-SECADI; 2012.

3. Mendes AM, Leite MS, Langdon EJ, Grisotti M. O desafio da atenção primária na saúde indígena no Brasil. Rev Panam Salud Publica 2018; 42:184.

4. Ministério da Saúde (MS). Secretaria Executiva. Coordenação Nacional de DST/AIDS. A Política do Ministério da Saúde para Atenção Integral a Usuários de Álcool e Outras Drogas. Brasília: MS; 2003.

5. Ministério da Saúde (MS). Portaria no 2.759, de 25 de outubro de 2007. Estabelece diretrizes gerais para a Política de Atenção Integral à Saúde Mental das Populações Indígenas e cria o Comitê Gestor. Diário Oficial da União; 2007.

6. Ghiggi Junior A, Langdon EJ. Reflexões sobre estratégias de intervenção a partir do processo de alcoolização e das práticas de autoatenção entre os índios Kaingang, Santa Catarina, Brasil. Cad Saude Publica 2014; 30(6):1-10.

7. Langdon EJ. O abuso de álcool entre os povos indígenas no Brasil: uma avaliação comparativa. In: Souza MLP, organizador. Processos de alcoolização indígena no Brasil: perspectivas plurais. Rio de Janeiro: Editora Fiocruz; 2013.

8. Menéndez EL. El proceso de alcoholización: revisión crítica de la producción socioantropológica, histórica y biomédica en América Latina. Cuaderno Casa Chata 1982; 57:61-94.

9. Souza MLP. Da prevenção de doenças à promoção da saúde: reflexões a partir da questão do uso de bebidas alcoólicas por indígenas. In: Souza MLP, organizador. Processos de alcoolização indígena no Brasil: perspectivas plurais. Rio de Janeiro: Editora Fiocruz; 2013. p. 108-126.

10. Menéndez EL. Etnografía y Alcoholismo: la construcción metodológica de um problema. In: Menéndez EL, editor. Prácticas e ideologías "científicas" y "populares" respecto del "alcoholismo" en México. México: CIESAS; 1992. p. 9-19.

11. Souza MLP, Garnelo L. Quando, como e o que se bebe: o processo de alcoolização entre povos indígenas do Alto Rio Negro, Brasil. In: Souza MLP, organizador. Processos de alcoolização indígena no Brasil: perspectivas plurais. Rio de Janeiro: Editora Fiocruz; 2013.

12. Grund JPG, Kaplan CHD, De Vries M. Rituales de regulación: el consumo controlado e incontrolado de las drogas en el marco natural. In: Heather N, Wodak A, Nadelmann E, O'Hare P. La cultura de las drogas en la sociedad del riesgo [livro na Internet]. Barcelona: Publicaciones Grup Igia; 2004. Disponível em: http:// www.grupigia.org/wp-content/uploads/CulturaDrogas.pdf

13. Minayo MCS. O desafio do conhecimento: pesquisa qualitativa em saúde. 8a ed. São Paulo: Hucitec; 2004.

14. Gadamer H-J. Verdade e método: Traços fundamentais de uma hermenêutica filosófica. Petrópolis: Vozes; 1999.

15. Melo MF. Hermenêutica e dialéctica: Gadamer e Habermas na metodologia das Ciências Sociais. Rev Angolana Soc 2012; 10:11-20.
16. Forte ECN, Pires DEP, Trigo SVVP, Martins MMFPS. A hermenêutica e o software ATLAS.TI: União promissora. Texto Contexto Enferm 2017; 26(4):e0350017.

17. Martorell-Poveda MA, Martinez-Hernaéz A, Canceller-Maicas N, Correa-Hurquiza M. Self-care strategies for emotional distress among young adults in Catalonia: a qualitative study. Int J Mental Health Syst 2015; 9:9.

18. Quilles MI. "Mansidão do fogo": aspectos etnopsicológicos do comportamento alcoólico entre os Bororo. In: Souza MLP, organizador. Processos de alcoolização indígena no Brasil: perspectivas plurais. Rio de Janeiro: Editora Fiocruz; 2013.

19. Souza MLP, Garnelo L. Quando, como e o que se bebe: o processo de alcoolização entre populações indígenas do alto Rio Negro, Brasil. Cad Saude Publica 2007; 23(7):1640-1648.

20. Dias LF. Consumo de bebidas alcoólicas entre os povos indígenas do Uaçá. In: Souza MLP, organizador. Processos de alcoolização indígena no Brasil: perspectivas plurais. Rio de Janeiro: Editora Fiocruz; 2013.

21. Fernandes JA. Cauinagens e Bebedeiras: os índios e o álcool na história do Brasil. In: Souza MLP, organizador. Processos de alcoolização indígena no Brasil: perspectivas plurais. Rio de Janeiro: Editora Fiocruz; 2013.

22. Ferreira LO. As boas palavras Mbyá-Guarani como caminho para a redução do uso de bebidas alcoólicas. In: Souza MLP, organizador. Processos de alcoolização indígena no Brasil: perspectivas plurais. Rio de Janeiro: Editora Fiocruz; 2013. p. 195-211.

23. Rivera CDP. La mala Hora: Articulaciones en el pluralismo médico de agricultores precordilleranos Aymaras Chilenos [tese]. Tarragona: Universitat Rovira i Virgili; 2015.

24. Vallverdú J. Religión, Política y Construcción Étnica en Chiapas, México. Rev Arxius Cien Sociales 2003; 9:137-153.

25. Oliveira RC, Nicolau BF, Levine A, Mendonça AVM, Videira V, Vargas AMD, Ferreira EF. "Tihik quando bebe Kaxmuk não tem pai, nem mãe, nem irmão": Percepções sociais das consequências do uso da cachaça no povo indígena Maxakali/MG/Brasil. Cien Saude Colet 2019; 24(8):2883-2894.

26. Maciel SC, Oliveira RCC, Melo JRF. Alcoolismo em Indígenas Potiguara: Representações Sociais dos Profissionais de Saúde. Psicol Cien Profissão 2012; 32(1):98-111.

27. Pedrana L, Trad LAB, Pereira LMG, Torrenté MON, Mota SEC. Análise crítica da interculturalidade na Política Nacional de Atenção às Populações Indígenas no Brasil. Rev Panam Salud Publica 2018; 42:e178.

28. Romaní O. Alcohol, sociedade y cultura. Jano: Med Humanidades 1993; 1.034:9-15.

29. Souza MLP, Garnelo L. Relativismo Cultural e Uso de Álcool: Contribuições a partir do campo da saúde indígena. In: Alarcon S, Jorge MAS, organizadores. Álcool e outras drogas: diálogos sobre um mal-estar contemporâneo. Rio de Janeiro: Fiocruz; 2012.

Artigo apresentado em 30/05/2019

Aprovado em 07/08/2019

Versão final apresentada em 27/11/2019 